\title{
openheart Does stress echocardiography add incremental value to baseline ejection fraction for the early identification of candidates for implantable defibrillators?
}

\author{
Josephine Muhrbeck, ${ }^{\oplus 1}$ Elif Gunyeli, ${ }^{1}$ Eva Andersson, ${ }^{1}$ Mahbubul Alam, ${ }^{2}$ \\ Viveka Frykman, ${ }^{1}$ Johanna Sjoblom ${ }^{1}$
}

To cite: Muhrbeck J, Gunyeli E, Andersson $\mathrm{E}$, et al. Does stress echocardiography add incremental value to baseline ejection fraction for the early identification of candidates for implantable defibrillators?. Open Heart 2019;6: 001053. doi:10.1136/ openhrt-2019-001053

Received 23 March 2019 Revised 10 May 2019 Accepted 13 June 2019
Check for updates

(C) Author(s) (or their employer(s)) 2019. Re-use permitted under CC BY-NC. No commercial re-use. See rights and permissions. Published by BMJ.

${ }^{1}$ Department of Clinical Sciences, Danderyd Hospital, Karolinska Institutet, Stockholm Sweden

${ }^{2}$ Department of Clinical Sciences, Danderyd Hospital, Karolinska Institutet, Stockholm, Sweden

Correspondence to Dr Josephine Muhrbeck josephine.muhrbeck@sll.se

\section{ABSTRACT}

Objective A reduction in left ventricular ejection fraction (EF) remains the strongest indicator of increased risk of sudden cardiac death after an acute myocardial infarction (AMI). Guidelines recommend that patients with an EF $\leq 35 \%, 6-12$ weeks after AMI should be considered for implantable cardioverter defibrillator (ICD) therapy. Stress echocardiography is a safe method to detect viability in a stunned myocardium. The purpose of this study was to investigate if stress echocardiography early after AMl could identify ICD candidates before discharge.

Methods Ninety-six patients with $\mathrm{EF} \leq 40 \%$ early after AMI were prospectively included in a cohort study, and investigated by baseline and stress echocardiography before discharge. Follow-up echocardiography was performed after 3 months. EF, mitral annular plane systolic excursion (MAPSE) and peak systolic velocity (PSV) were determined for each examination.

Results There were $80(83 \%)$ patients who completed the baseline, stress and follow-up echocardiography. Among them there were 32 (40\%) patients who met the ICD criteria of EF $\leq 35 \%$ at 3 months. For these patients, EF, MAPSE and PSV were significantly lower than for those patients who recovered. The area under the receiver operating characteristic curve (AUC) was $85 \%$ (95\% Cl 0.74 to 0.94 ) for baseline EF to predict non-recovery. None of the other variables had a higher AUC.

Conclusion Patients who met the ICD criteria of EF $\leq 35 \%$ at 3 months after myocardial infarction had lower EF, MAPSE and PSV on baseline and stress echocardiograph before discharge. Stress echocardiography did not add additional value in predicting non-recovery.

\section{INTRODUCTION}

Sudden cardiac death (SCD) remains a main threat to patients after an acute myocardial infarction (AMI). Despite vast effort to determine other predictors of SCD, heart failure, expressed as a reduction in left ventricular ejection fraction $(\mathrm{EF})$, remains the strongest indicator of an increased risk. ${ }^{1}$ Although the

\section{Key questions}

What is already known about this subject?

- Implantable defibrillators save lives in the setting of ischaemic heart failure. The benefit is, however, not seen until a period of expectation after a myocardial infarction, during which the affected myocardium may or may not recover. The risk of sudden cardiac death is higher during the initial weeks after a myocardial infarction, and therefore it would be beneficial to find objective parameters to guide clinicians for early implantation of implantable defibrillators.

What does this study add?

- In this study, simple and commonly used echocardiographic systolic parameters were studied before and during low-dose dobutamine stress echocardiography within days after an acute myocardial infarction. Patients who met the criteria for implantable cardioverter defibrillator after 3 months had significantly lower baseline ejection fraction, mitral annular plane systolic excursion and peak velocities. However, low-dose dobutamine stress echocardiography did not add any additional prognostic value.

How might this impact on clinical practice?

- For patients where there is uncertainty regarding the definition of ejection fraction, other parameters such as mitral annular plane systolic excursion and peak systolic velocity could add prognostic information. Low-dose dobutamine stress echocardiography did however, not add information to standard resting echocardiography.

incidence of heart failure due to myocardial ischemia has declined due to improved medical and surgical therapies, development of heart failure is still common after myocardial infarction, affecting almost $30 \%$ of such patients. $^{2}$

For patients with at least moderately reduced $\mathrm{EF}$ after a myocardial infarction, primary prophylactic therapy with an implantable 
cardioverter defibrillator (ICD) improves survival. ${ }^{3} 4$ However, in two major studies, the survival benefit was observed only after several months to years; more than 6 months had passed since the AMI for approximately $75 \%$ of patients in the MADIT study ${ }^{3}$ and $87 \%$ in the MADIT-II study. ${ }^{4}$ Implantation of an ICD to all patients with an $\mathrm{EF} \leq 35 \%$ early (within 40 days) after myocardial infarction does not seem to affect overall mortality. ${ }^{56}$ Current international guidelines therefore recommend that only patients with an EF $\leq 35 \%$ at reassessment echocardiography 6-12 weeks after infarction should be considered for ICD therapy. ${ }^{1}$ This period of expectation remains a clinical challenge; if the risk of SCD is highest early after a myocardial infarction, why does early implantation of an ICD not save lives? As time progresses after the index infarction, many patients with a reduced systolic heart failure improve their EF due to relief of myocardial stunning, ${ }^{78}$ and it is difficult to predict who will improve their $\mathrm{EF}$ over time and, more importantly, who will not.

Low-dose dobutamine stress echocardiography is a safe and non-invasive method to detect viability in a stunned myocardium. ${ }^{9}$ For simplicity, this will be referred to as 'stress echocardiography' in this paper. In stress echocardiography, regional wall motion is assessed during baseline and at stress. With administration of the sympathomimetic drug dobutamine, the myocardial contractility increases if the myocardium is viable. This is visible by an increased wall motion of the segment of interest. Permanently damaged necrotic myocardium is not affected. However, the evaluation of stress echocardiography is challenging as movement of individual segments of the myocardium is affected by neighbouring segments. Objective global quantification of the longitudinal motion of the mitral annular plane (mitral annular plane systolic excursion, MAPSE), peak systolic velocity of the mitral plane (PSV) and EF are parameters that reflect myocardial contractility. For stress echocardiography in patients with thrombolytic treatment after myocardial infarction, an increase in MAPSE $\geq 2 \mathrm{~mm}$ has been associated with recovery of EF after 18 months. ${ }^{10}$

The main objective of this study is to evaluate the use of early stress echocardiography, more specifically if the response in EF, MAPSE and PSV to low-dose dobutamine is a better predictor of non-recovery of EF at 3 months than baseline EF among patients with heart failure after a myocardial infarction.

\section{METHODS}

We conducted a prospective cohort study among 96 patients admitted to hospital for AMI at two teaching hospitals in Stockholm, Sweden. Patients who were $>18$ years old with an $\mathrm{EF} \leq 40 \%$ on routine echocardiography within 1 week of infarction were eligible for inclusion. The rationale for including patients with EF up to $40 \%$ was that the EF of some patients is reduced over time due to the fact of ischaemic remodelling of the left ventricle, and such patients might thus still be future candidates for ICD implantation. Exclusion criteria were short life expectancy $(<1$ year) based on clinical information and comorbidity, which would also be contraindicative of ICD implantation, or if more than 8 days had passed since the AMI.

Baseline and stress echocardiography were performed before discharge, and follow-up echocardiography was performed 3 months after the AMI. A team of three biomedical analysts performed all echocardiographic examinations using commercially available equipment, Vivid 7 (GE Vingmed, Norway). For stress echocardiography, dobutamine was administered intravenously as a continuous infusion of up to $10 \mu \mathrm{g} / \mathrm{kg} / \mathrm{min}$. Standard apical views of the left ventricle and tissue Doppler loops were acquired for each patient. If less than $80 \%$ of the endocardial border was visualised, a contrast agent (Sonovue; Bracco) was used. After baseline images were acquired, a starting dose of dobutamine $5 \mu \mathrm{g} / \mathrm{kg} / \mathrm{min}$ was administered for $3 \mathrm{~min}$. After $3 \mathrm{~min}$, the dobutamine infusion was increased to $10 \mu \mathrm{g} / \mathrm{kg} / \mathrm{min}$, and after an additional $3 \mathrm{~min}$, stress images were acquired. All examinations were recorded and stored digitally and analysed using software Echo Pac (GE Vingmed).

Measurements of the MAPSE and PSVs were collected from the tissue Doppler images. For MAPSE, an average of the longitudinal excursions of the anterolateral and inferoseptal walls (from the apical four-chamber view), and the inferior and anterior walls (from the apical two-chamber view) was used. This was technically beneficial over the use of M-mode since PSV was also to be measured from these loops. M-mode measurements and colour-coded tissue Doppler imaging for measurements of MAPSE have shown close correlation in healthy subjects. ${ }^{11}$ For PSV, an average was calculated using all six basal segments visualised in the three apical views. EF was quantified by the Simpson biplane method from the apical four-chamber and two-chamber views. For EF assessments, two independent members of the research team independently performed all the measurements. If there was less than a 5-percentage-unit discrepancy, a mean value of the two was recorded as the consensus value of $\mathrm{EF}$. If a discrepancy of more than 5 percentage units was found, a third reviewer proceeded with the analysis and a consensus was reached. Intra-observer and inter-observer analyses were performed.

The main outcome variable was $\mathrm{EF} \leq 35 \%$ at the 3-month echocardiography.

All baseline characteristics and coronary angiography reports were collected at baseline and at follow-up.

A sample size calculation was performed assuming a baseline $\mathrm{EF}$ of $30 \%$. In order to detect a 10 percentage unit difference at follow-up, a sample size of 80 patients was required with significance level of 0.05 and power of $80 \%$. Assuming a drop-out rate of approximately $20 \%$, we aimed to include 100 patients in this study.

Categorical variables were presented as numbers and percentages. For comparisons, the $\chi^{2}$ test was used, unless the expected count was 5 or lower at which time 
Fisher's exact test was used. All continuous variables were tested for normality with the Shapiro-Wilk test and by visually reviewing histograms. Normally distributed continuous variables, for which the mean was presented, were compared by the paired t-test for dependent variables or independent t-test for independent variables. For non-normally distributed data, for which the median and IQR were presented, the Wilcoxon rank-sum test was used.

Receiver operating characteristic (ROC) curves were graphed and the area under the ROC curves (AUCs) presented. AUCs were compared by the DeLong method. Curves were reviewed and cut-off levels were identified for the continuous predictors. The sensitivity, specificity, positive predictive value and negative predictive value for each predictor were presented. For all analyses, complete case analyses were performed.

\section{RESULTS}

In summary, 96 patients were included between 2010 and 2013. Of the 96 patients, three patients did not do the baseline and stress echocardiography; one due to cardiac arrest and prolonged stay in the coronary care unit, one due to multiple premature ventricular contractions and one due to withdrawal of consent. Of the remaining 93 patients who did the baseline and stress echocardiography, 13 patients did not do the 3-month follow-up echocardiography (two patients due to death), thus leaving 80 patients $(81 \%)$ for the complete case analysis. A flowchart describing the reasons for dropping out is found in figure 1.

Baseline characteristics are summarised in table 1. Most of the patients were men $(76 \%)$ and the median age was 70.5 years (IQR 62-76.5). Both the mean and median EF at the baseline study echocardiography was 32\% (SD 7.0, IQR 28-35). Most patients were admitted for ST-segment elevation myocardial infarction (STEMI, $61 \%)$. There were $92(96 \%)$ patients who underwent coronary angiography, and $84(88 \%)$ received revascularisation therapy by either percutaneous coronary

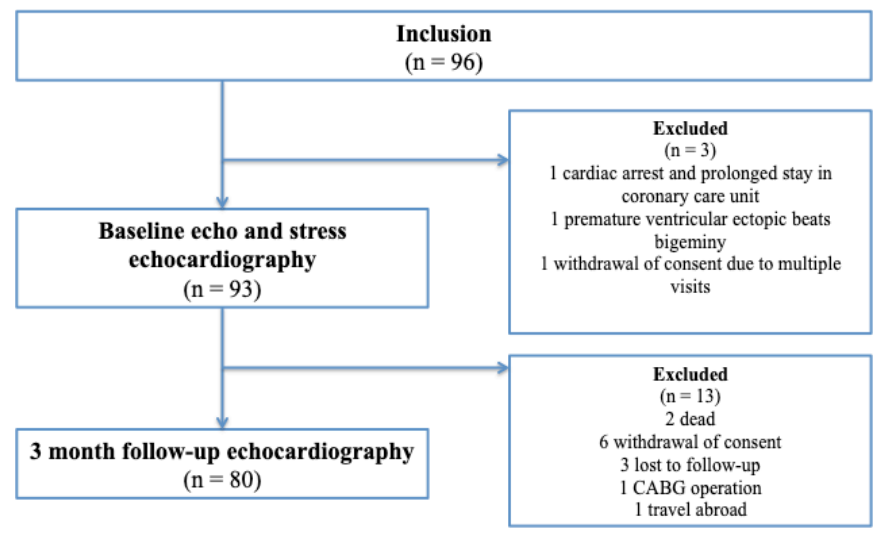

Figure 1 Outline of study participants and echocardiographic examinations. CABG, coronary artery bypass graft. intervention (PCI) or coronary artery bypass graft $(\mathrm{CABG})$. For completeness, the baseline characteristics were also grouped according to complete case or drop-out. Drop-out patients were more often women and had less often received PCI during the index infarction. A larger proportion of drop-out patients had three-vessel disease. Although baseline EF did not differ between the groups, baseline MAPSE, baseline PSV, stress EF and stress PSV were significantly lower among those who did not complete both examinations.

Median time from myocardial infarction to the baseline and stress echocardiography was 4 days (IQR 3-6). Mean EF increased from $32 \pm 7$ at baseline to $40 \pm 11$ during stress echocardiography $(\mathrm{p}<0.001)$ and to $40 \pm 10(\mathrm{p}<0.001$ compared with baseline) at 3 months. Mean MAPSE and mean PSV increased significantly during stress echocardiography (from 7 to $8 \mathrm{~mm}(\mathrm{p}<0.001)$ and 4 to $5 \mathrm{~cm} / \mathrm{s}$ $(\mathrm{p}<0.001)$, respectively). The intra-observer and inter-observer variabilities in EF quantifications were calculated as the absolute variability by calculating the absolute differences between the observations. ${ }^{12}$ Using this method, the intra-observer variability was $5 \pm 4$ percentage units and the inter-observer variability was $5 \pm 5$ percentage units.

Characteristics and echocardiographic parameters of the 80 patients who completed both examinations, separated by outcome, are found in table 2. Patients who had an EF $\leq 35 \%$ at 3 months more often had a previous history of myocardial infarction and had less often received PCI treatment for the index infarction compared with patients who improved their EF. Also, the EF, MAPSE and PSV were significantly lower at both baseline and during stress echocardiography for these patients. The average increase in EF during stress echocardiography was significantly lower in the group meeting the ICD criteria; median 5 (IQR -2 to 11 ) versus 9 (IQR $5-13)$ percentage units $(p=0.021)$. Contractile reserve, here defined as an increase in EF of 5 percentage units, ${ }^{13}$ was seen in $37(77 \%)$ of the patients who improved their EF compared with $16(50 \%)$ of patients meeting the ICD criteria $(p=0.012)$.

ROC curves for the different echocardiographic variables in determining an $\mathrm{EF}>35 \%$ are displayed in figure 2 . The highest AUC was found for baseline EF of 0.85 (95\% CI 0.74 to 0.94 ), although the AUC for EF during stress echocardiography was not statistically different at 0.80 (95\% CI 0.70 to 0.90$), \mathrm{p}=0.310$. All other AUCs were significantly lower. None of the studied AUCs changed significantly when stratifying for previous interventions or atrial fibrillation. The difference in AUC between baseline EF and EF during stress echocardiography was also not significant for patients with STEMI $(\mathrm{p}=0.639)$ or patients with non-STEMI $(p=384)$. Since patients assigned for $\mathrm{CABG}$ were not revascularised at the time of the baseline and stress echocardiographies, and because of the possible later recovery of $\mathrm{EF}$ in these patients, comparisons of AUCs were also performed excluding these patients $(n=5)$. Similar to the overall results, there was no difference in baseline EF and EF during stress 
Table 1 Baseline characteristics and echocardiographic results of the 96 patients completing the first study echocardiography including the low-dose dobutamine stress echocardiography and separated by completeness

\begin{tabular}{|c|c|c|c|c|}
\hline & $\begin{array}{l}\text { Total } \\
(\mathrm{n}=96)\end{array}$ & $\begin{array}{l}\text { Complete } \\
(\mathrm{n}=80)\end{array}$ & $\begin{array}{l}\text { Drop-out } \\
(n=16)\end{array}$ & $P$ value \\
\hline \multicolumn{5}{|l|}{ Demographics } \\
\hline Gender, male & $73(76)$ & $65(81)$ & $8(50)$ & 0.008 \\
\hline Smoking, current & $29(30)$ & $23(29)$ & $6(38)$ & 0.487 \\
\hline Hypertension & $46(48)$ & $39(49)$ & $7(44)$ & 0.715 \\
\hline Previous heart failure & $15(16)$ & $12(15)$ & $3(19)$ & 0.711 \\
\hline Previous myocardial infarction & $13(14)$ & $11(14)$ & $2(13)$ & 1.000 \\
\hline Previous revascularisation & $11(12)$ & $8(10)$ & $3(19)$ & 0.386 \\
\hline Atrial fibrillation & $13(14)$ & $12(15)$ & $1(6)$ & 0.688 \\
\hline Chronic kidney disease & $5(5)$ & $5(6)$ & $0(0)$ & 0.586 \\
\hline Diabetes mellitus & $19(20)$ & $13(16)$ & $6(38)$ & 0.051 \\
\hline Previous stroke & $7(7)$ & $4(5)$ & $3(19)$ & 0.098 \\
\hline \multicolumn{5}{|l|}{ Index infarction } \\
\hline Admitted for STEMI & $59(61)$ & $52(65)$ & $7(44)$ & 0.111 \\
\hline Angiography during hospital admission & $92(96)$ & $80(100)$ & $12(75)$ & 0.001 \\
\hline No of coronary arteries with significant stenoses & $1.9 \pm 0.9$ & $1.8 \pm 0.8$ & $2.1 \pm 1.2$ & 0.334 \\
\hline Three-vessel disease * & $26(28)$ & $19(24)$ & $7(58)$ & 0.033 \\
\hline Left main stem stenosis * & $10(11)$ & $9(11)$ & $1(8)$ & 1.000 \\
\hline LAD stenosis * & $73(79)$ & $63(79)$ & $10(83)$ & 0.715 \\
\hline CX stenosis * & $42(46)$ & $35(44)$ & $7(58)$ & 0.370 \\
\hline RCA stenosis * & $46(50)$ & $38(48)$ & $8(67)$ & 0.354 \\
\hline $\mathrm{PCl}$ treatment for index infarction & $79(85)$ & $73(91)$ & $6(38)$ & $<0.001$ \\
\hline CABG treatment for index infarction & $7(7)$ & $5(6)$ & $2(13)$ & 0.330 \\
\hline \multicolumn{5}{|l|}{ Echocardiographic data } \\
\hline Baseline EF, \%, mean \pm SD & $32 \pm 7$ & $32 \pm 7$ & $29 \pm 6$ & 0.144 \\
\hline Baseline MAPSE, mm, median [IQR] & $7[6-8]$ & $7[6-8]$ & $6[5-6]$ & 0.020 \\
\hline Baseline PSV, cm/s, mean \pm SD & $3.7 \pm 1.0$ & $3.8 \pm 1.0$ & $3.2 \pm 0.5$ & 0.018 \\
\hline Stress EF, \%, median [IQR] & 41 [31-48] & 42 [31-50] & 35 [32-40] & 0.080 \\
\hline Stress MAPSE, mm, mean \pm SD & $8 \pm 2$ & $8 \pm 2$ & $7 \pm 2$ & 0.159 \\
\hline Stress PSV, cm/s, median [IQR] & $4.9[3.8-5.8]$ & $5.1[4.1-6.0]$ & $4.2[3.3-4.7]$ & 0.025 \\
\hline Malignant arrhythmias within 3 months & $7(7)$ & $6(8)$ & $1(6)$ & 1.000 \\
\hline
\end{tabular}

All numbers are presented as $\mathrm{n}(\%)$ if not otherwise stated.

*Percentage among patients who underwent coronary angiography.

CABG, coronary artery bypass graft; CX, circumflex artery; EF, ejection fraction; IQR, interquartile range; LAD, left anterior descending artery; MAPSE, mitral annular plane systolic excursion; PCI, percutaneous coronary intervention; PSV, peak systolic velocity; RCA, right coronary artery; SD, standard deviation; STEMI, ST-segment elevation myocardial infarction.

echocardiography $(\mathrm{p}=0.300)$, whereas the AUCs for all other curves were significantly lower.

In order to account for the combined predictive value of baseline and stress echocardiography, the baseline EF was multiplied with the stress echocardiography EF, MAPSE and PSV, respectively. None of the multiplicative variables had higher AUC than baseline EF. The AUC for $\mathrm{EF} \times \mathrm{EF}$ was 0.85 (95\% CI 0.75 to 0.94 ), for $\mathrm{EF} \times \mathrm{MAPSE}$ $0.80(95 \%$ CI 0.70 to 0.90$)$ and for EF $\times$ PSV 0.75 (95\% CI 0.64 to 0.86$)$.
For all studied systolic echocardiographic parameters, the sensitivity, specificity, and positive and negative predictive values were calculated. Relevant variables and combination of variables are presented in table 3 .

During the follow-up period of 3 months, two patients died, one due to stroke and the other due to heart failure. There were seven patients who developed ventricular arrhythmias requiring defibrillation. Among them, one patient had sustained ventricular tachycardia and was sedated and defibrillated. All others had ventricular 
Table 2 Summary of baseline characteristics, according to outcome

\begin{tabular}{|c|c|c|c|}
\hline & $\begin{array}{l}\mathrm{EF} \leq 35 \% \text { at } 3 \text { months } \\
\mathrm{N}=32\end{array}$ & $\begin{array}{l}\text { EF }>35 \% \text { at } 3 \text { months } \\
\mathrm{N}=48\end{array}$ & $P$ value \\
\hline \multicolumn{4}{|l|}{ Baseline characteristics } \\
\hline Male gender, n (\%) & $27(84)$ & $38(79)$ & 0.559 \\
\hline Age, years, mean \pm SD & $69 \pm 9.7$ & $67 \pm 10.6$ & 0.491 \\
\hline Hypertension & $17(53)$ & $22(46)$ & 0.523 \\
\hline Heart failure & $8(25)$ & $4(8)$ & 0.056 \\
\hline Atrial fibrillation & $6(19)$ & $6(13)$ & 0.443 \\
\hline Diabetes & $5(16)$ & $8(17)$ & 1.000 \\
\hline Chronic kidney failure & $2(6)$ & $3(6)$ & 1.000 \\
\hline Previous AMI & $8(25)$ & $3(6)$ & 0.023 \\
\hline Previous revascularisation & $4(13)$ & $4(8)$ & 0.707 \\
\hline Admitted for STEMI & $18(56)$ & $30(63)$ & 0.576 \\
\hline Three-vessel disease & $10(31)$ & $9(19)$ & 0.198 \\
\hline LAD stenosis & $26(81)$ & $37(77)$ & 0.655 \\
\hline $\mathrm{PCl}$ & $25(78)$ & $47(98)$ & 0.004 \\
\hline CABG & $3(9)$ & $2(4)$ & 0.381 \\
\hline \multicolumn{4}{|l|}{ Echo parameters } \\
\hline EF baseline, $\%$, median [IQR] & 28 [24-32] & 35 [33-39] & $<0.001$ \\
\hline MAPSE, baseline, mm, mean $\pm S D$ & $6 \pm 1$ & $8 \pm 2$ & 0.003 \\
\hline PSV, baseline, $\mathrm{cm} / \mathrm{s}$, mean \pm SD & $3.4 \pm 0.8$ & $4.1 \pm 1.0$ & 0.002 \\
\hline Stress EF, mean \pm SD & $33 \pm 10$ & $44 \pm 10$ & $<0.001$ \\
\hline Stress MAPSE, mean \pm SD & $7 \pm 1$ & $9 \pm 2$ & 0.005 \\
\hline Stress PSV, mean \pm SD & $4.6 \pm 1.1$ & $5.4 \pm 1.8$ & 0.042 \\
\hline EF increase $\geq 5$ percentage units & $16(50)$ & $37(77)$ & 0.012 \\
\hline EF absolute difference* ${ }^{\star} \mathrm{mm}$, mean $\pm \mathrm{SD}$ & $5 \pm 8$ & $9 \pm 7$ & 0.021 \\
\hline MAPSE absolute difference*, mean \pm SD & $1 \pm 1$ & $1 \pm 1$ & 0.401 \\
\hline PSV absolute difference ${ }^{\star}$, mean \pm SD & $1.3 \pm 0.9$ & $1.4 \pm 1.1$ & 0.556 \\
\hline EF relative difference*, median [IQR] & $17[-7$ to 43$]$ & $25[15-36]$ & 0.622 \\
\hline MAPSE relative difference ${ }^{\star}$, mean $\pm S D$ & $18 \pm 20$ & $18 \pm 20$ & 0.876 \\
\hline PSV relative difference*, mean \pm SD & $40 \pm 32$ & $35 \pm 25$ & 0.408 \\
\hline
\end{tabular}

All values are presented as number (percentage) if not otherwise stated.

*Difference refers to the difference between resting values and values measured during stress echocardiography.

AMI, acute myocardial infarction; CABG, coronary artery bypass graft; EF, ejection fraction; IQR, interquartile range; LAD, left anterior descending artery; MAPSE, mitral annular plane systolic excursion; PCl, percutaneous coronary intervention; PSV, peak systolic velocity; SD, standard deviation; STEMI, ST-segment elevation myocardial infarction.

fibrillation or torsade de pointes and cardiopulmonary resuscitation was performed. All seven patients survived the malignant ventricular arrhythmia and were offered and received ICDs. The median time from the myocardial infarction to the ventricular arrhythmia was 12 days (total range, 2-53 days) and the median time from ventricular arrhythmia to ICD implantation was 4 days (total range, 0-15 days). A description of the main baseline and echocardiographic characteristics are found in table 4 .

\section{DISCUSSION}

Although patients who met the ICD criteria of EF $\leq 35 \%$ at 3 months after myocardial infarction had lower EF,
MAPSE and PSV on baseline and stress echocardiograph, the stress echocardiography did not add additional value in predicting non-recovery in this study. Baseline EF has been shown in previous studies to be a strong predictor of having $\mathrm{EF} \leq 35 \%$ at follow-up at 3 months. ${ }^{14}$ A large multicentre study, aiming to assess $\mathrm{EF}$ and clinical predictors of EF recovery 90 days after an acute myocardial infarction, found that patients with an $\mathrm{EF} \leq 25 \%$ early after the infarction had an almost threefold increased chance of recovery, OR 2.77 (95\% CI 1.34 to 5.70). ${ }^{14}$ Other predictors, such as previous myocardial infarction and increased troponin levels, had trends towards significant ORs, but were not significant. This, in congruence to our finding 

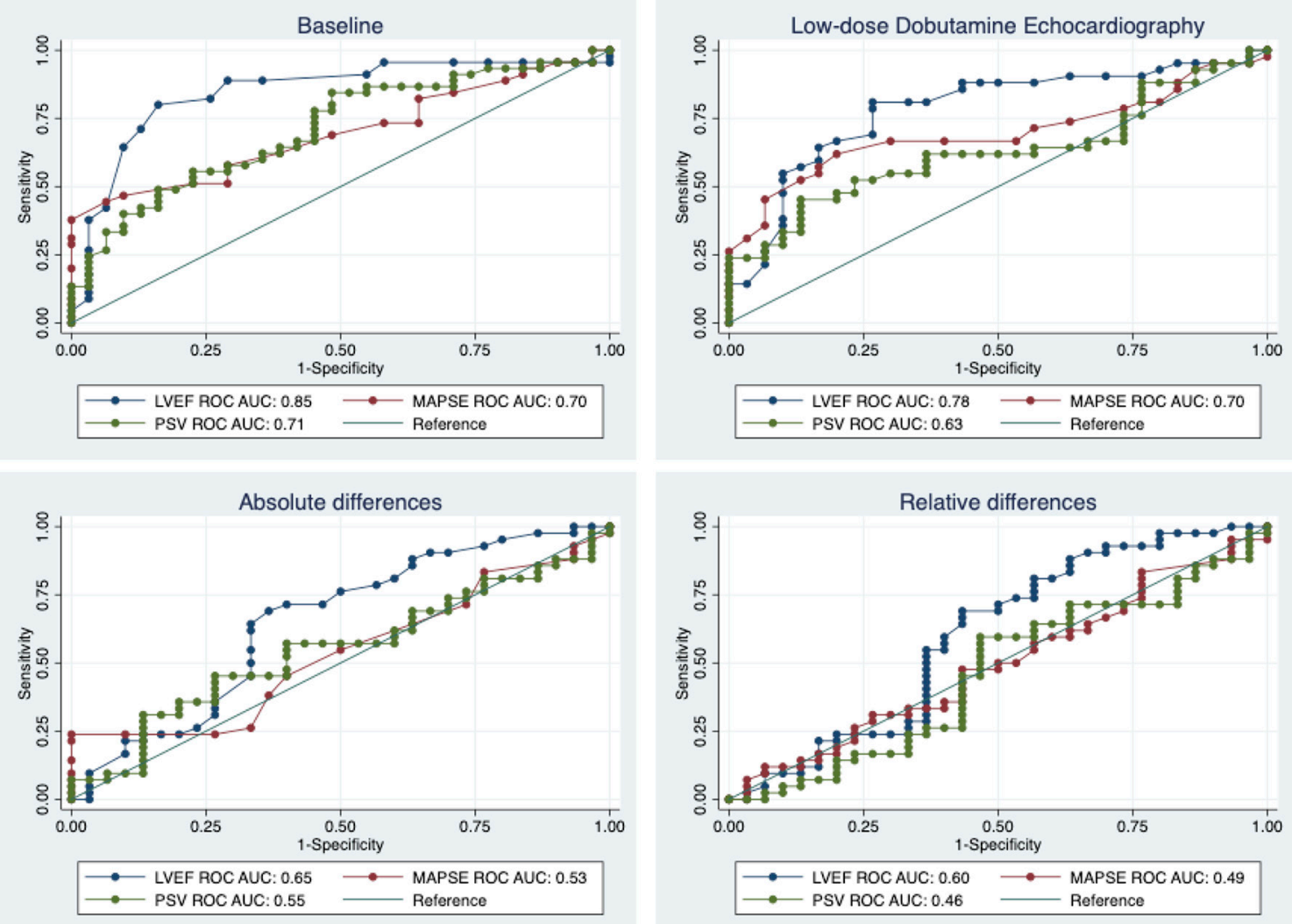

Figure 2 Receiver operating characteristic (ROC) curves of the various predictors determining ejection fraction (EF) $>35 \%$ at 3 months. AUC, area under the ROC curve; LVEF, left ventricular ejection fraction; MAPSE, mitral annular plane systolic excursion; PSV, peak systolic velocity.

of the highest AUC for baseline EF, supports the fact that $\mathrm{EF}$ indeed is a strong predictor.

One reason that the difference in $\mathrm{EF}$ at rest and on dobutamine administration did not add additional predictive value to the EF-based outcome could lie in the difficulty of determining EF itself. Patients with poor image quality will always be a challenge during evaluation of echocardiographic examinations. Contrast agents

Table 3 Sensitivity, specificity, positive predictive values and negative predictive values for different cut-off levels of the echocardiographic parameters

\begin{tabular}{|c|c|c|c|c|c|}
\hline & Tested positive & Sensitivity & Specificity & PPV & NPV \\
\hline \multicolumn{6}{|l|}{ Baseline } \\
\hline$E F \leq 35 \%$ & $59 / 80$ & 93.75 & 39.58 & 50.85 & 90.48 \\
\hline MAPSE $\leq 8 \mathrm{~mm}$ & $54 / 76$ & 93.55 & 44.44 & 53.70 & 90.91 \\
\hline$P S V \leq 5 \mathrm{~cm} / \mathrm{s}$ & $69 / 76$ & 96.77 & 13.33 & 43.48 & 85.71 \\
\hline \multicolumn{6}{|l|}{ LDE } \\
\hline$E F \leq 45 \%$ & $50 / 80$ & 90.62 & 56.25 & 58.00 & 90.00 \\
\hline MAPSE $\leq 9 \mathrm{~mm}$ & $51 / 72$ & 93.33 & 45.24 & 54.90 & 90.48 \\
\hline $\mathrm{PSV} \leq 6 \mathrm{~cm} / \mathrm{s}$ & $56 / 72$ & 90.00 & 30.95 & 48.21 & 81.25 \\
\hline EF difference $\leq 10$ percentage units & $55 / 80$ & 75.00 & 35.42 & 43.64 & 68.00 \\
\hline MAPSE difference $\leq 2 \mathrm{~mm}$ & $59 / 72$ & 90.00 & 23.81 & 45.76 & 76.92 \\
\hline PSV difference $\leq 1 \mathrm{~cm} / \mathrm{s}$ & $30 / 72$ & 40.00 & 57.14 & 40.00 & 57.14 \\
\hline \multicolumn{6}{|l|}{ Combination variables } \\
\hline Baseline EF $\leq 35$ and baseline PSV $\leq 5$ and baseline MAPSE $\leq 8$ & $43 / 76$ & 83.87 & 62.22 & 60.47 & 84.85 \\
\hline Baseline $\mathrm{EF} \leq 35$ and stress $\mathrm{EF} \leq 45$ & $45 / 80$ & 87.50 & 64.58 & 62.22 & 88.57 \\
\hline
\end{tabular}

EF, ejection fraction; LDE, Low-dose Dobutamine Echocardiography

; MAPSE, mitral annular plane systolic excursion; NPV, negative predictive value; PPV, positive predictive value; PSV, peak systolic velocity. 
Table 4 Comparison between patients with and without malignant ventricular arrhythmias requiring defibrillation within 3 months

\begin{tabular}{|c|c|c|c|}
\hline & $\begin{array}{l}\text { Malignant } \\
\text { ventricular } \\
\text { arrhythmias } \\
(n=7)\end{array}$ & $\begin{array}{l}\text { No malignant } \\
\text { ventricular } \\
\text { arrhythmia } \\
(\mathrm{n}=89)\end{array}$ & $P$ value \\
\hline Age (years) & $69 \pm 4$ & $69 \pm 11$ & 0.860 \\
\hline Male gender & $7(100)$ & $66(74)$ & 0.191 \\
\hline Hypertension & $4(57)$ & $42(47)$ & 0.612 \\
\hline Heart failure & $1(14)$ & $14(16)$ & 1.000 \\
\hline Atrial fibrillation & $0(0)$ & $13(15)$ & 0.599 \\
\hline Diabetes & $1(14)$ & $18(20)$ & 1.000 \\
\hline Kidney failure & $0(0)$ & $5(6)$ & 1.000 \\
\hline Previous AMI & $2(29)$ & $11(12)$ & 0.240 \\
\hline Previous PCl & $1(14)$ & $10(11)$ & 0.586 \\
\hline STEMI & $4(57)$ & $51(57)$ & 1.000 \\
\hline Treated with PCl & $7(100)$ & $72(83)$ & 0.593 \\
\hline $\begin{array}{l}\text { Baseline } \mathrm{EF}, \% \text {, } \\
\text { mean } \pm \mathrm{SD}\end{array}$ & $32 \pm 9$ & $32 \pm 7$ & 0.864 \\
\hline $\begin{array}{l}\text { Baseline MAPSE, } \\
\text { mm, mean } \pm \text { SD }\end{array}$ & $8 \pm 2$ & $7 \pm 2$ & 0.390 \\
\hline $\begin{array}{l}\text { Baseline PSV, } \\
\mathrm{cm} / \mathrm{s} \text {, mean } \pm \mathrm{SD}\end{array}$ & $4 \pm 1$ & $4 \pm 1$ & 0.670 \\
\hline $\begin{array}{l}\text { Stress EF, \%, } \\
\text { mean } \pm \mathrm{SD}\end{array}$ & $39 \pm 15$ & $39 \pm 10$ & 0.856 \\
\hline $\begin{array}{l}\text { Stress MAPSE, } \\
\mathrm{mm}, \text { mean } \pm \text { SD }\end{array}$ & $8 \pm 1$ & $8 \pm 2$ & 0.515 \\
\hline $\begin{array}{l}\text { Stress PSV, } \mathrm{cm} / \mathrm{s} \text {, } \\
\text { median [IQR] }\end{array}$ & $6[5-7]$ & $5[4-6]$ & 0.104 \\
\hline $\begin{array}{l}\mathrm{EF} \text { at } 3 \text { months, } \\
\% \text {, median }[\mathrm{IQR}]\end{array}$ & 30 [25-55] & 40 [33-47] & 0.458 \\
\hline $\begin{array}{l}\text { Patients with } \\
\text { EF } \leq 35 \% \text { at } 3 \\
\text { months, n (\%) }\end{array}$ & $4(57)$ & $29(39)(n=74)$ & 0.435 \\
\hline
\end{tabular}

All values are presented as number (percentage) if not otherwise stated.

AMI, acute myocardial infarction; EF, ejection fraction; MAPSE, mitral annular plane systolic excursion; $\mathrm{PCl}$, percutaneous coronary intervention; PSV, peak systolic velocity; STEMI, STsegment elevation myocardial infarction.

were used to improve visualisation of the endocardial border, but not for all patients. The clear visualisation of the endocardium is very important in the calculation of EF, which was used (in different settings) both as a predictor variable and the main outcome variable. In order to have an as accurate measurement of EF as possible, this was performed by at least two readers and analysis of intra-observer and inter-observer variability was acceptable. However, using the Simpson Biplane method excludes the inferolateral and anteroseptal wall (the apical three-chamber view), which could influence EF calculations. It is possible that $3 \mathrm{D}$ echocardiography could have affected the results as it does not require any geometrical assumptions. However, this was not available at the time of the study.

The measurements of MAPSE and PSV are more robust measurements than $\mathrm{EF}$ and are not as sensitive to an unclear visualisation of the myocardium. Although the AUC for both MAPSE and PSV, during both baseline and stress echocardiography, was lower than that for EF, a cut-off of MAPSE $8 \mathrm{~mm}$ had similar sensitivity and negative predictive value as a cut-off of $\mathrm{EF} \leq 35 \%$. It is possible that this parameter could be used as further clinical assistance when distinguishing high-risk patients from low-risk patients.

During low-dose stress echocardiography, stress was induced by the administration of intravenous dobutamine after which baseline and stress images are compared. A time duration cut-off of in total 6 min of dobutamine infusion was used as endpoint for the stress echocardiography. We did not investigate other commonly reported endpoints for the stress test, such as increase in stroke volume or heart frequency. The rationale for this was the benefit of all patients receiving the same workload. There was, however, a significant increase in $\mathrm{EF}$ at group level before and after the administration of dobutamine, indicating increased contractility. Also, only low-dose dobutamine stress echocardiography was performed, as the main point of interest was to establish increased contractility. Many studies have addressed the association between viability detected by early stress echocardiography after a myocardial infarction and functional recovery of the left ventricle. ${ }^{1516}$ Although there seems to be a general consensus that stress echocardiography can be used to predict late left ventricular functional recovery, ${ }^{17}$ and also can be used as a predictor for re-infarction and mortality risks ${ }^{18-20}$ there are still some concerns. First, most of the previous studies were relatively small and performed during an era where thrombolytic therapy was the dominant method of reperfusion. Second, in many of these studies, the baseline EF was relatively high thus including patients who were at relatively low risk. Third, there is a vast discrepancy of the outcome measurement of left ventricular recovery both in terms of what parameter was measured and also when the recovery was meant to take place, making comparisons and generalisations difficult.

Strain and strain rate are parameters describing myocardial deformation and have been shown to have prognostic value in several cardiac conditions. A recent publication demonstrated that impaired global longitudinal strain by speckle tracking was independently associated with first ICD therapy for patients with structural heart disease with such device, with a HR of $1.94(95 \% \mathrm{CI}$ 1.30 to $2.91, \mathrm{p}<0.001) .{ }^{21}$ However, measurement of strain and strain rate require high image quality and frame rate, and cannot be used when the contrast preset has been used. Therefore, we were not able to perform such measurements.

The study population is among the frailest patient groups after a myocardial infarction. Patients with the highest morbidity or most severe heart failure after the 
myocardial infarction might not have accepted inclusion in the study, thus possibly introducing a selection bias in the study. It is possible, but not certain, that the patients with lowest EF after a myocardial infarction are at the highest risk of not improving their EF. If so, this selection bias would lead to an underestimation of the patients meeting the outcome of $\mathrm{EF} \leq 35 \%$ at 3 months.

Although patients who met the ICD criteria of EF $\leq 35 \%$ at 3 months after myocardial infarction had lower EF, MAPSE and PSV on baseline echocardiography and low-dose stress echocardiography, the stress echocardiography did not add additional value in predicting non-recovery.

Acknowledgements The authors would like to express their gratitude to Professor M Rosenqvist, Dr N Witt and to the echo teams at the South Hospital and Danderyd Hospital for their support in this work. This project received funding from the Swedish Heart Lung Foundation and from Medtronic.

Contributors JM performed many of the echocardiographic measurements, did the statistical analyses and drafted the first version of the manuscript. EG analysed the echocardiographic examinations and helped revise the manuscript. EA performed most of the echocardiographic examinations and did the measurements of the examinations. MA, VF and JS designed the study and included and followed the study participants. They also contributed to the manuscript.

Funding This study was supported by grants from The Swedish Heart Lung Foundation, Stockholm, Sweden and Medtronic, Stockholm, Sweden.

Competing interests None declared.

Patient consent for publication Obtained.

Ethics approval This study is conducted in accordance to the Declaration of Helsinki and was approved by the Regional Ethical Review Board in Stockholm, Sweden (2010/882-31/2).

Provenance and peer review Not commissioned; externally peer reviewed.

Data availability statement No data are available.

Open access This is an open access article distributed in accordance with the Creative Commons Attribution Non Commercial (CC BY-NC 4.0) license, which permits others to distribute, remix, adapt, build upon this work non-commercially, and license their derivative works on different terms, provided the original work is properly cited, appropriate credit is given, any changes made indicated, and the use is non-commercial. See: http://creativecommons.org/licenses/by-nc/4.0/.

\section{REFERENCES}

1. Priori SG, Blomström-Lundqvist C, Mazzanti A, et al. 2015 ESC guidelines for the management of patients with ventricular arrhythmias and the prevention of sudden cardiac death: The Task Force for the Management of Patients with Ventricular Arrhythmias and the Prevention of Sudden Cardiac Death of the European Society of Cardiology (ESC). Endorsed by: Association for European Paediatric and Congenital Cardiology (AEPC). Eur Heart J 2015;36:2793-867.

2. Desta L, Jernberg T, Löfman I, et al. Incidence, temporal trends, and prognostic impact of heart failure complicating acute myocardial infarction. The SWEDEHEART registry (Swedish Web-System for enhancement and development of evidence-based care in heart disease evaluated according to recommended therapies): a study of 199,851 patients admitted with index acute myocardial infarctions, 1996 to 2008. JACC Heart Fail 2015;3:234-42.
3. Moss AJ, Hall WJ, Cannom DS, et al. Improved survival with an implanted defibrillator in patients with coronary disease at high risk for ventricular arrhythmia. Multicenter Automatic Defibrillator Implantation Trial Investigators. N Engl J Med 1996;335:1933-40.

4. Moss AJ, Zareba W, Hall WJ, et al. Prophylactic implantation of a defibrillator in patients with myocardial infarction and reduced ejection fraction. N Engl J Med 2002;346:877-83.

5. Hohnloser SH, Kuck KH, Dorian P, et al. Prophylactic use of an implantable cardioverter-defibrillator after acute myocardial infarction. N Engl J Med 2004;351:2481-8.

6. Steinbeck G, Andresen D, Seidl K, et al. Defibrillator implantation early after myocardial infarction. N Engl J Med 2009;361:1427-36.

7. Ottervanger JP, van 't Hof AW, Reiffers S, et al. Long-term recovery of left ventricular function after primary angioplasty for acute myocardial infarction. Eur Heart J 2001;22:785-90.

8. Sjöblom J, Muhrbeck J, Witt N, et al. Evolution of left ventricular ejection fraction after acute myocardial infarction: implications for implantable cardioverter-defibrillator eligibility. Circulation 2014;130:743-8.

9. Piérard LA, De Landsheere CM, Berthe $C$, et al. Identification of viable myocardium by echocardiography during dobutamine infusion in patients with myocardial infarction after thrombolytic therapy: comparison with positron emission tomography. J Am Coll Cardiol 1990;15:1021-31.

10. Samad BA, Alam M. Effects of low-dose dobutamine on displacement of the atrioventricular plane and assessment of myocardial viability in patients with acute myocardial infarction treated with thrombolysis. Echocardiography 1999;16:17-25.

11. Ballo P, Bocelli A, Motto A, et al. Concordance between M-mode, pulsed tissue Doppler, and colour tissue Doppler in the assessment of mitral annulus systolic excursion in normal subjects. Eur $J$ Echocardiogr 2008;9:748-53.

12. Popović ZB, Thomas JD. Assessing observer variability: a user's guide. Cardiovasc Diagn Ther 2017;7:317-24.

13. Agricola E, Oppizzi M, Pisani M, et al. Stress echocardiography in heart failure. Cardiovasc Ultrasound 2004;2.

14. Brooks GC, Lee BK, Rao R, et al. Predicting persistent left ventricular dysfunction following myocardial infarction: the PREDICTS study. $J$ Am Coll Cardiol 2016;67:1186-96.

15. Mauro VM, Cianciulli TF, Prezioso HA, et al. Dobutamine stress echocardiography can predict reversible ventricular dysfunction after acute myocardial infarction. Clin Cardiol 2005;28:523-8.

16. Monin JL, Garot J, Scherrer-Crosbie M, et al. Prediction of functional recovery of viable myocardium after delayed revascularization in postinfarction patients: accuracy of dobutamine stress echocardiography and influence of long-term vessel patency. J Am Coll Cardiol 1999;34:1012-9.

17. van Loon RB, Veen G, Kamp O, et al. Left ventricular remodeling after acute myocardial infarction: the influence of viability and revascularization - an echocardiographic substudy of the VIAMI-trial. Trials 2014;15.

18. van der Sijde JN, Boiten HJ, van Domburg RT, et al. Longterm ( $>10$ years) prognostic value of dobutamine stress echocardiography in a high-risk cohort. Am J Cardiol 2016;117:1078-83.

19. Sicari R, Picano E, Landi P, et al. Prognostic value of dobutamineatropine stress echocardiography early after acute myocardial infarction. Echo Dobutamine International Cooperative (EDIC) study. J Am Coll Cardiol 1997;29:254-60.

20. Picano E, Pingitore A, Sicari R, et al. Stress echocardiographic results predict risk of reinfarction early after uncomplicated acute myocardial infarction: large-scale multicenter study. Echo Persantine International Cooperative (EPIC) Study Group. J Am Coll Cardiol 1995;26:908-13.

21. Guerra F, Malagoli A, Contadini D, et al. Global longitudinal strain as a predictor of first and subsequent arrhythmic events in remotely monitored ICD patients with structural heart disease. JACC Cardiovasc Imaging 2019. doi:10.1016/j.jcmg.2018.12.020. [Epub ahead of print: 13 Feb 2019]. 